OPEN ACCESS

Edited by:

Satoru Suzuki,

Ehime University, Japan

Reviewed by:

Juntao Wang

Research Centre

for Eco-Environmental Science, China

Carles Borrego,

Catalan Institute for Water Research,

Spain

${ }^{*}$ Correspondence:

Sven Jechalke

Sven.Jechalke@julius-kuehn.de

${ }^{\dagger}$ Present address:

Samuel Jacquiod,

Agroécologie, AgroSup Dijon, INRA,

Université Bourgogne,

Franche-Comté, France

Specialty section:

This article was submitted to Antimicrobials, Resistance

and Chemotherapy,

a section of the journal

Frontiers in Microbiology

Received: 07 February 2019

Accepted: 22 March 2019

Published: 16 April 2019

Citation:

Blau K, Jacquiod $S$, Sørensen SJ, Su J-Q, Zhu Y-G, Smalla K and Jechalke $S$ (2019) Manure and Doxycycline Affect the Bacterial

Community and its Resistome in Lettuce Rhizosphere and Bulk Soil.

Front. Microbiol. 10:725.

doi: 10.3389/fmicb.2019.00725

\section{Manure and Doxycycline Affect the Bacterial Community and Its Resistome in Lettuce Rhizosphere and Bulk Soil}

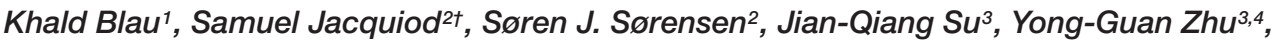 \\ Kornelia Smalla ${ }^{1}$ and Sven Jechalke ${ }^{1 *}$
}

1 Julius Kühn-Institut-Federal Research Centre for Cultivated Plants, Institute for Epidemiology and Pathogen Diagnostics, Braunschweig, Germany, ${ }^{2}$ Section of Microbiology, Department of Biology, University of Copenhagen, Copenhagen, Denmark, ${ }^{3}$ Key Lab of Urban Environment and Health, Institute of Urban Environment, Chinese Academy of Sciences, Xiamen, China, ${ }^{4}$ State Key Lab of Urban and Regional Ecology, Research Center for Eco-Environmental Sciences, Chinese Academy of Sciences, Beijing, China

Manure application to agricultural soil introduces antibiotic residues and increases the abundance of antibiotic-resistant bacteria (ARB) carrying antibiotic resistance genes (ARGs), often located on mobile genetic elements (MGEs). The rhizosphere is regarded as a hotspot of microbial activity and gene transfer, which can alter and prolong the effects of organic fertilizers containing antibiotics. However, not much is known about the influence of plants on the effects of doxycycline applied to soil via manure. In this study, the effects of manure spiked with or without doxycycline on the prokaryotic community composition as well as on the relative abundance of ARGs and MGEs in lettuce rhizosphere and bulk soil were investigated by means of a polyphasic cultivation-independent approach. Samples were taken 42 days after manure application, and total community DNA was extracted. Besides a pronounced manure effect, doxycycline spiking caused an additional enrichment of ARGs and MGEs. High-throughput quantitative PCR revealed an increase in tetracycline, aminoglycoside, and macrolide-lincosamide-streptogramin B (MLSB) resistance genes associated with the application of manure spiked with doxycycline. This effect was unexpectedly lower in the rhizosphere than in bulk soil, suggesting a faster dissipation of the antibiotic and a more resilient prokaryotic community in the rhizosphere. Interestingly, the tetracycline resistance gene tet $A(P)$ was highly enriched in manure-treated bulk soil and rhizosphere, with highest values observed in doxycycline-treated bulk soil, concurring with an enrichment of Clostridia. Thus, the gene $\operatorname{tet} A(\mathrm{P})$ might be a suitable marker of soil contamination by ARB, ARGs, and antibiotics of manure origin. These findings illustrate that the effects of manure and doxycycline on ARGs and MGEs differ between rhizosphere and bulk soil, which needs to be considered when assessing risks for human health connected to the spread of ARGs in the environment.

Keywords: manure, bulk soil, lettuce rhizosphere, resistance genes, prokaryotic community, high-throughput quantitative polymerase chain reaction 


\section{INTRODUCTION}

Antimicrobial resistance is a serious public health problem that threatens the achievements of modern medicine (WHO, 2014). Enormous amounts of veterinary antibiotics have been used worldwide in animal husbandry to promote growth and to treat or prevent bacterial diseases (Arikan et al., 2007). Therefore, manure application to agricultural soils introduces not only a mixture of different nutrients and organic matter that improves the growth of plants (Aust et al., 2009) but also antibiotic-resistant bacteria (ARB) carrying antibiotic resistance genes (ARGs), often located on mobile genetic elements (MGEs), together with residuals of veterinary antibiotic compounds and their degradation products (Sarmah et al., 2006; Heuer and Smalla, 2007; Ding et al., 2014; Jechalke et al., 2014; Wolters et al., 2016, 2018; Yang et al., 2017). A number of studies have demonstrated that manure-derived ARB and their ARGs may persist in soil for a few weeks and up to years and that these ARGs can be horizontally transferred into native soil bacteria (Haack and Andrews, 2000; Chee-Sanford et al., 2001; Schmitt et al., 2006; Heuer and Smalla, 2007; Heuer et al., 2008, 2011a; Binh et al., 2009; Jechalke et al., 2013b; Udikovic-Kolic et al., 2014; Wichmann et al., 2014). Furthermore, the application of antibiotic-containing manure to agricultural soils can result in increasing levels of ARGs and the selection of resistant pathogens (Heuer and Smalla, 2007; Schwaiger et al., 2009; Heuer et al., 2011a; Looft et al., 2012; Wellington et al., 2013). This antibiotic selection pressure is assumed to play a key role in the spread of ARGs by means of vertical and horizontal gene transfer (HGT). Thus, several studies have shown that sub-therapeutic levels of antibiotics, as commonly observed in soil, promote the abundance of ARB, because these concentrations of antibiotics can provide a selective advantage to ARB, thus leading to shifts in the composition of bacterial communities (Ghosh and LaPara, 2007; Gullberg et al., 2011; Alexander et al., 2013; Xiong et al., 2015) and even to the development of high level resistance (Wistrand-Yuen et al., 2018).

Tetracyclines, discovered in the 1940s, are among the most commonly used antibiotics in animal farming (Chopra and Roberts, 2001) and have long been used against a wide range of Gram-negative and Gram-positive bacterial pathogens (Chopra and Roberts, 2001; Chee-Sanford et al., 2009). Doxycycline, a member of the tetracycline class of antibiotics, was frequently detected in manure (Tylová et al., 2010; Carballo et al., 2016; van den Meersche et al., 2016; Widyasari-Mehta et al., 2016; Wolters et al., 2016; Albero et al., 2018). In a previous study, we could demonstrate that the application of high doses of doxycycline-spiked manure to agricultural soils was correlated with an enrichment of ARGs and class 1 integrons and with changes in the soil bacterial community composition, more pronounced in sandy compared to loamy soil (Blau et al., 2017). However, only a small selection of genes was quantified and changes in the bacterial community were assessed by denaturing gradient gel electrophoresis (DGGE), not providing qualitative information on potential responders to the antibiotic spiked to manure. Furthermore, it is not known so far if plants can alter the fate and effects of doxycycline in the rhizosphere and phyllosphere compared to bulk soil, which should be considered when assessing associated risks for human health.

In the rhizosphere of plants, physicochemical properties and the availability of root exudates are assumed to be important drivers for the development of a plant-specific microbiota (Smalla et al., 2001; Schreiter et al., 2014). Furthermore, the plant rhizosphere is considered to be a hotspot of HGT, which seems to be modulated by root growth and exudates production, increasing microbial abundance and activity (van Elsas et al., 2003; Mølbak et al., 2007; Heuer and Smalla, 2012). Accordingly, it was observed in previous studies that the fate and effects of antibiotics in the rhizosphere can differ from bulk soil (Rosendahl et al., 2011; Jechalke et al., 2013a,b; Chen et al., 2018). However, this was not shown so far for doxycycline. More importantly, ARB and residual antibiotics derived from manure amendments to soil could foster the transfer of ARGs into bacterial communities associated to crops, ultimately posing the risk of antibiotic resistance transmission to the human microbiota.

In the present study, a greenhouse experiment was performed to determine the effects of doxycycline-spiked manure on the resistome, MGEs, and the soil prokaryotic community composition in bulk soil and lettuce rhizosphere. Therefore, selected ARGs and MGEs were quantified in rhizosphere, bulk soil, and manure, as well as in the phyllosphere by the use of conventional quantitative real-time PCR (TaqMan-based). Additionally, the abundance and diversity of ARGs and MGEs were analyzed by high-throughput quantitative PCR (HT-qPCR) with 296 primer sets including 285 ARGs, 8 transposase genes, 2 class 1 integron integrase genes, and the bacterial 16S rRNA gene, and the results of the two approaches were compared regarding their sensitivity. In parallel, effects on the prokaryotic community composition in bulk soil and rhizosphere were analyzed by Illumina MiSeq sequencing of 16S rRNA genes, amplified from TC-DNA.

\section{MATERIALS AND METHODS}

\section{Properties of Soil and Manure}

The soil used for the experiment was silty sand obtained from Landwirtschaftliche Untersuchungs- und Forschungsanstalt Speyer (LUFA Speyer, Speyer, Germany ${ }^{1}$ ). The soil has not been treated with manure, pesticides, or biocidal fertilizers for at least five years. The collected soil was air-dried and sieved with a pore diameter of $2 \mathrm{~mm}$. The physicochemical properties of the soil used in this study were as follows: $\mathrm{pH}$ value $\left(0.01 \mathrm{M} \mathrm{CaCl}_{2}\right) 4.9$, organic carbon $0.71 \%$, nitrogen $0.06 \%$, and cation-exchange capacity $4.2(\mathrm{meq} / 100 \mathrm{~g})$. Manure was obtained from a pig husbandry farm in Lower Saxony, Germany. The collected manure was stored at $4^{\circ} \mathrm{C}$ until the beginning of the experiment. The concentration of doxycycline in the manure was below $1 \mathrm{mg} \mathrm{kg}^{-1}$ wet weight (Blau et al., 2017). The manure was characterized by the LUFA Nord-West (Hameln, Germany). It had a dry weight of $3.8 \%$, total N $10.1 \%$,

\footnotetext{
${ }^{1}$ www.lufa-speyer.de
} 
$\mathrm{NH}_{4}^{+} 4.7 \%, \mathrm{P} 3.6 \%, \mathrm{~K} 8.1 \%, \mathrm{Mg}^{2+} 1.0 \%$, Ca $6.2 \%$, and $\mathrm{S} 1.3 \%$. Furthermore, the manure contained $664.1 \mathrm{mg} \mathrm{Cu} \mathrm{kg}^{-1}$ and $1,998 \mathrm{mg} \mathrm{Zn} \mathrm{kg}^{-1}$. Manure samples were collected in triplicate, placed in $15-\mathrm{ml}$ falcon tubes, and stored at $-20^{\circ} \mathrm{C}$ until DNA extraction was performed.

\section{Experimental Design}

The experiment was conducted in a greenhouse. The microcosms were set up using polypropylene pots, each containing $300 \mathrm{~g}$ of soil (dry weight). Each treatment included three replicates and was designated as (i) untreated bulk soil (BS-C) and rhizosphere (R-C), (ii) manure-treated bulk soil (BS-M) and rhizosphere (R-M) without antibiotic, and (iii) manure-treated bulk soil and rhizosphere supplemented with doxycycline (50 or $100 \mathrm{mg} \mathrm{kg}$ soil dry weight) (BS-M-D50 or BS-MD100 and R-M-D50 or R-M-D100, respectively). Doxycycline stock solution (Doxycycline Hyclate, purity > 98\%, SigmaAldrich, Munich, Germany) was prepared by dissolving the compound in water with subsequent sterile filtering $(0.2 \mu \mathrm{m})$. Forty grams of manure per kilogram of soil was applied as previously described, corresponding to a realistic input according to agricultural practice (Heuer et al., 2011b). Before mixing with the soil, the manure was spiked with the antibiotic stock solution. Untreated and manure-treated soils served as controls to assess the effects of manure and of doxycycline, respectively.

The lettuce (Lactuca sativa L. cv. Tizian) seeds were sown in small pots and pre-grown for four weeks. The seedlings in the three-leaf stage were transplanted to the pots with the different soil treatments, directly after mixing the soil with manure or doxycycline-spiked manure. All microcosms were incubated for 6 weeks at $20^{\circ} \mathrm{C}$ in the greenhouse with 16 -h light. Water was added as needed, and the pots were sampled on day 42 .

\section{Sampling of Bulk Soil, Lettuce Rhizosphere, and Phyllosphere}

On day 42, lettuce rhizosphere and bulk soil samples were taken by removing the lettuce plants from the soil. Loosely bound soil was shaken off the roots. The soil sticking to the roots after shaking was considered rhizosphere. The residual soil in the pots was thoroughly mixed and was considered bulk soil. One gram of bulk soil or root with adhering rhizosphere soil was weighed and transferred into centrifugation tubes $(50 \mathrm{ml})$. The prokaryotic cells were extracted by adding $3 \mathrm{ml}$ of sterile $0.3 \% \mathrm{NaCl}$ solution and mixing on the vortex. This step was repeated three times, and the supernatants $(3 \times 3 \mathrm{ml})$ were combined in new $50-\mathrm{ml}$ centrifugation tubes and centrifuged at 3,100 $\times \mathrm{g}$ for $15 \mathrm{~min}$ at $4^{\circ} \mathrm{C}$. The pellets were stored at $-20^{\circ} \mathrm{C}$ until DNA extraction.

Phyllosphere samples were obtained by cutting the leaves with a sterile scalpel and weighing $5 \mathrm{~g}$ of the cut samples in to sterile Stomacher ${ }^{\circledR}$ bags. The samples were mixed with $15 \mathrm{ml}$ of $0.3 \% \mathrm{NaCl}$ solution three times and homogenized for 1 min at high speed using a Stomacher ${ }^{\circledR} 400$ (Seward, Worthing, United Kingdom). The supernatants were combined and centrifuged at $3,100 \times g$ for $15 \mathrm{~min}$ at $4^{\circ} \mathrm{C}$. The pellets were stored at $-20^{\circ} \mathrm{C}$ until DNA extraction.

\section{DNA Extraction and Purification}

Total community (TC)-DNA was extracted from $0.1 \mathrm{~g}$ of homogenized soil or rhizosphere pellets and from $0.1 \mathrm{~g}$ of manure by using the FastDNA ${ }^{\circledR}$ SPIN Kit for soil (MP Biomedicals, Heidelberg, Germany) according to the manufacturer's instructions. The phyllosphere pellets were taken as a whole and DNA extraction was performed as described for the bulk soil and rhizosphere pellets. The extracted TC-DNA samples were purified using the GeneClean ${ }^{\circledR}$ Spin Kit (MP Biomedicals), following the manufacturer's recommendations. The quality of extracted DNA was determined by agarose gel electrophoresis. The extracted DNA was stored at $-20^{\circ} \mathrm{C}$ until further analysis.

\section{Detection and Quantification of Target Genes via Real-Time qPCR}

Selected genes were quantified in TC-DNA from manure, bulk soil, rhizosphere, and phyllosphere by quantitative real-time PCR 5 '-nuclease assays (TaqMan qPCR) in a CFX96 real-time PCR detection system (Bio-Rad, Hercules, CA, United States). The targeted genes included intI1 and intI2 for class 1 and 2 integron integrase genes; korB specific for IncP-1 plasmids; $q a c E$ and/or qacE $\Delta 1$ ( $q a c E / q a c E \Delta 1$ ) encoding quaternary ammonium compound resistance; aadA encoding streptomycin and spectinomycin resistance; tet $(\mathrm{W}), \operatorname{tet}(\mathrm{Q}), \operatorname{tet}(\mathrm{A})$, and tet $(\mathrm{M})$ encoding tetracycline resistance; and sull encoding sulfonamide resistance. The $16 \mathrm{~S}$ rRNA genes were quantified by using the primers BACT1369F and PROK1492R and the probe TM1389F. The primers, qPCR conditions, and references are listed in Supplementary Table S1. The relative abundances of ARGs and MGEs were calculated as copy number of ARG or MGE divided by the copy number of $16 \mathrm{~S}$ rRNA genes and subsequent log transformation. Due to co-extracted plant DNA interfering with the quantification of the bacterial 16S rRNA genes, for the phyllosphere samples, the absolute abundances of the ARGs were determined and expressed as gene copies per gram of leaf. The Pearson correlation coefficient ( $\mathrm{r}$ ) and $p$-values between the relative abundance of ARGs and concentrations of antibiotics were tested by using the CORR procedure of the SAS statistical package $(p<0.05$; SAS 9.3; SAS Institute, Inc., Cary, NC, United States). Comparisons between pairs of data were made using the GLIMMIX procedure (Tukey test, $p<0.05$; SAS 9.3).

\section{High-Throughput Quantitative PCR}

HT-qPCR was performed for the purified TC-DNA extracted from bulk soil and rhizosphere treatments (BS-C, BS-M, BSM-D100, and R-M-D100) as well as from one manure sample. Therefore, the HT-qPCR was performed using the WaferGen SmartChip Real-time PCR system (WaferGen Bio-systems, Inc., United States) as described previously (Su et al., 2015) with slight modifications. Each PCR reaction (100 nl each well) consisted of $1 \times$ LightCycler 480 SYBR Green I Master (Roche Applied Sciences, Indianapolis, IN, United States), $1 \mathrm{mg} \mathrm{ml}^{-1}$ bovine serum albumin (New England Biolaboratories, Beverly, MA, United States), $500 \mathrm{nM}$ of each primer, and DNA template of $2.5 \mathrm{ng} \mathrm{ul}^{-1}$. In total, 296 primer sets were used targeting 284 ARGs for major classes of antibiotics, 8 transposase genes, 
2 class 1 integron integrase genes (including the clinical class 1 integron), the bla $a_{\mathrm{NDM}-1}$ gene, and the 16S rRNA gene (Su et al., 2015).

The results of the qPCR runs were pre-processed as described previously, amplifications beyond the range of $90-110 \%$ were discarded, and only amplifications in all three technical replicates were considered positive (Su et al., 2015). The gene copy number was estimated (Eq. 1) as described recently (Ouyang et al., 2015). The fold change compared to the controls was calculated by a comparative CT method (Eqs 2-4) as previously described (Schmittgen and Livak, 2008; Zhu et al., 2013). For the calculation of fold changes, controls below the detection limit of threshold cycle (CT) 31 or without amplification were replaced by CT 31 . For soil, the detection of enriched genes in one treatment only or shared within treatments was visualized by a Venn diagram created by using the R package "VennDiagram."

$$
\begin{aligned}
& \text { Gene copy number }=10^{\left(\left(31-\mathrm{C}_{\mathrm{T}}\right) /(10 / 3)\right)} \\
& \Delta \mathrm{C}_{\mathrm{T}}=\mathrm{C}_{\mathrm{T}(\mathrm{ARG})}-\mathrm{C}_{\mathrm{T}(16 \mathrm{~S})} \\
& \Delta \Delta \mathrm{C}_{\mathrm{T}}=\Delta \mathrm{C}_{\mathrm{T}(\text { Treatment })}-\Delta \mathrm{C}_{\mathrm{T}(\text { Control })} \\
& \text { Fold change }=2^{\left(-\Delta \Delta \mathrm{C}_{\mathrm{T}}\right)}
\end{aligned}
$$

Genes were considered significantly enriched compared to the BS-C soil if the range created by two standard deviations of the mean fold change was entirely $>1$ (Su et al., 2015). Genes of different treatments were considered to differ in fold change if their calculated upper and lower ranges did not overlap.

\section{Prokaryotic Community Analysis Using Illumina MiSeq Sequencing}

The prokaryotic community compositions of bulk soil and lettuce rhizosphere samples as well as of the manure used in the experiment were analyzed by Illumina MiSeq sequencing (three replicates each). A fragment of the bacterial 16S rRNA gene was amplified using the primers $341 \mathrm{~F} \quad\left(5^{\prime}\right.$-CCTAYGGGRBGCASCAG-3') and 806R $\left(5^{\prime}\right.$ GGACTACNNGGGTATCTAAT-3') flanking the 460-bp variable V3-V4 region of the target group Prokaryotes including domains of Archaea and Bacteria (Jacquiod et al., 2017). The resulting amplicons were amplified in a second step using the same primers with attached adaptors and barcode tags as previously described (Nunes et al., 2016). The amplification products were purified, and products smaller than $100 \mathrm{bp}$ were removed using the Agencourt AMPure XP beads (Beckman Coulter, Brea, CA, United States) according to the manufacturer's instructions. The concentrations of the purified amplicons were measured using a Qubit Fluorometer (Life Technologies, Carlsbad, CA, United States). Subsequently, samples were pooled, adjusted to equimolar concentrations, and concentrated using the DNA Clean and Concentrator-5 kit (Zymo Research, Irvine, CA, United States). Finally, the samples were subjected to $2 \times 250$ bp paired-end high-throughput sequencing on an Illumina ${ }^{\circledR}$ MiSeq ${ }^{\circledR}$ platform (Illumina, San Diego, CA, United States). The obtained sequences were trimmed, clustered, and annotated using a previously described methodology (Nunes et al., 2016).
Unassembled raw amplicon data were submitted to the NCBI Sequence Read Archive under the Accession No. PRJNA521325.

The sequences were demultiplexed using the MiSeq Controller software and trimming of the diversity spacers was performed using biopieces ${ }^{2}$. Mate-pairing and filtering of the sequences was performed using usearch v7.0.1090 (Edgar, 2010). Clustering of OTUs, dereplication, and removal of singletons were performed using uparse (Edgar, 2013). Chimeras were removed using usearch and the ChimeraSlayer package (Haas et al., 2011). Representative sequences for each OTU were defined using Mothur v.1.25.0 with a threshold of 0.8 (Schloss et al., 2009). To build a unifrac phylogenetic tree, Greengenes (DeSantis et al., 2006) with QIIME wrappers for PyNAST (Caporaso et al., 2010a), FastTree (Price et al., 2010), and alignment filtering (Caporaso et al., 2010b) were used. Sequence contingency tables were exported at the species level for bacteria using a 97\% similarity threshold. The total number of quality filtered OTUs obtained for each replicate is given in Supplementary Table S2, and the rarefaction curves for each replicate are shown in Supplementary Figure S1.

The prokaryotic community composition between samples was compared by principal component analysis (PCA) using the R package "labdsv" and the pca() function (Roberts, 2016), based on relative abundance of OTUs. For the analysis of differences between manure-treated bulk soil and rhizosphere and the effect of the antibiotic treatments (D0, D50, and D100) as well as their interactions, a permutation test (10,000 permutations) was performed on OTU level with the R package "vegan" (Oksanen et al., 2018) and the function "adonis." Pairwise distances were calculated using Bray-Curtis dissimilarity. Significant procaryotic responders to the doxycycline treatment at the genus level in bulk soil and lettuce rhizosphere were determined by the R package "edgeR" using the function glmLRT (Robinson et al., 2010; McCarthy et al., 2012). The alpha-diversity indices (Chao's richness, Pielou's evenness, and Shannon's diversity) were calculated as described in Babin et al. (2018). In short, read count data of each sample were 100 times randomly subsampled to the least amount of sequences per sample $(n=4,811)$ and analyzed using the R package "vegan." Figures showing the relative abundance of OTUs at the phylum and class level were created with the R package "pheatmap" (Klode, 2019).

\section{RESULTS}

\section{TaqMan-Based Quantification of ARGs and MGEs in Bulk Soil, Rhizosphere, Phyllosphere, and Manure}

In TC-DNA from bulk soil and rhizosphere without manure application (BS-C and R-C), only genes $\operatorname{korB}$, sul1, intI1, and $q a c E / q a c E \Delta 1$ were detected (Figure 1 and Supplementary Table S3). In contrast, tet(Q), tet(W), tet(M), tet(A), qacE/qacE $\Delta 1$, korB, aadA, sul1, and integrase gene intI1 were detected in TC-DNA from all manure-amended soils, except for intI2, which was not detected (Figure $\mathbf{1}$ and

\footnotetext{
${ }^{2}$ www.biopieces.org
} 

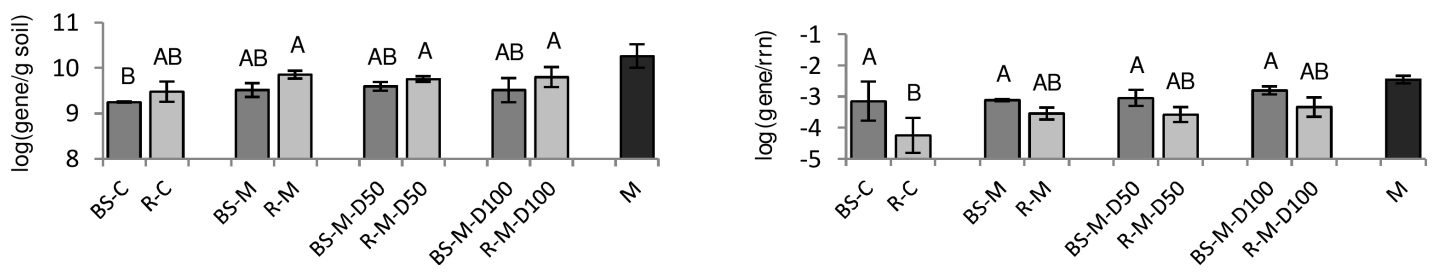

korB

$\operatorname{aad} A$
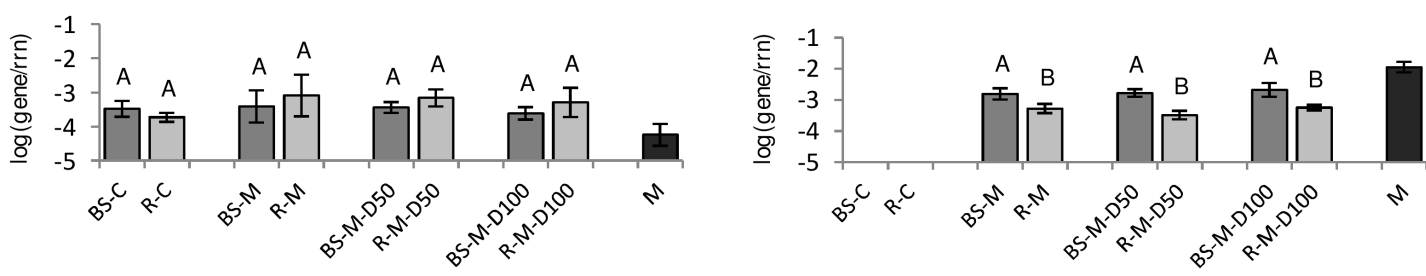

sul1

qacE/qacE $\Delta 1$
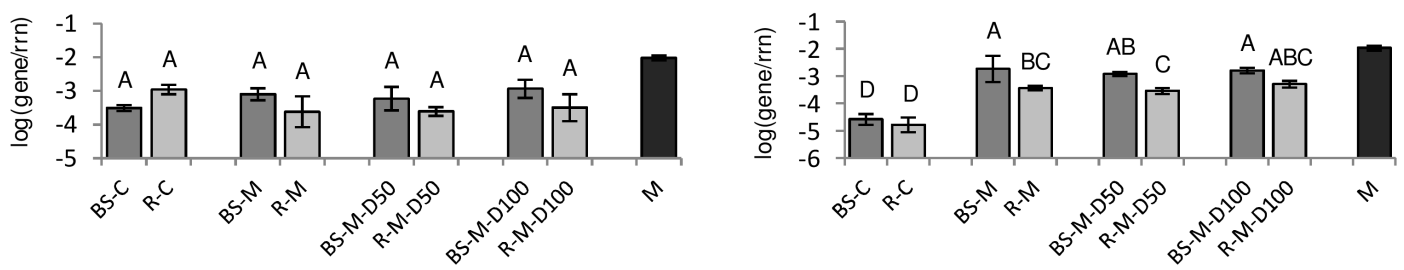

$\operatorname{tet}(\mathrm{A})$

tet(W)
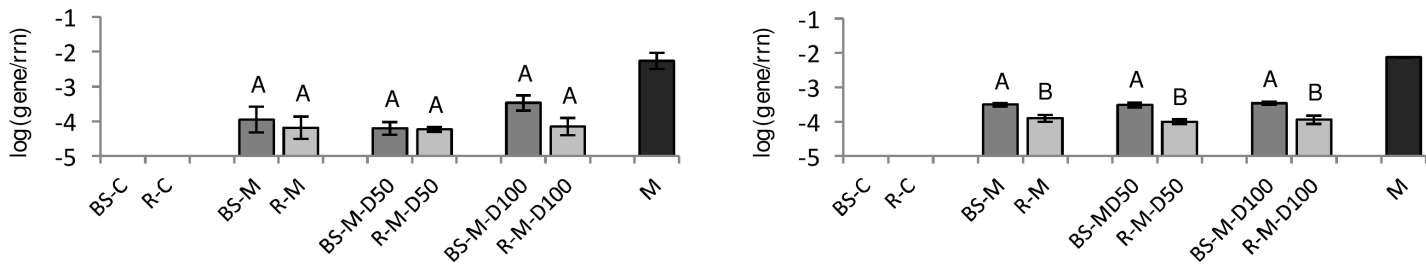

$\operatorname{tet}(\mathrm{Q})$

$\operatorname{tet}(\mathrm{M})$
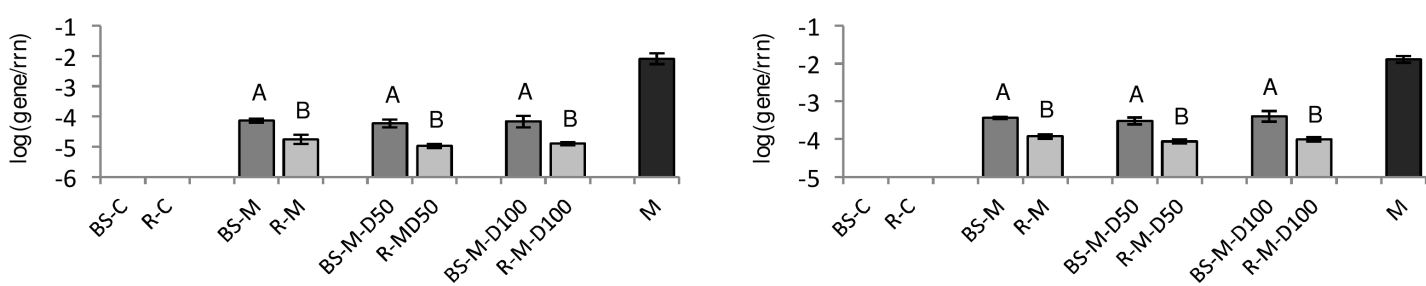

FIGURE 1 | The abundance of the resistance genes, class 1 integron integrase gene, and korB specific for IncP-1 plasmids present in lettuce rhizosphere (R, light gray), bulk soil (BS, dark gray), and manure (M, black), obtained by TaqMan-based quantitative PCR (qPCR), relative to $16 S$ rRNA genes (rrn). Error bars indicate the standard deviations of three replicates. Different letters indicate significant differences between soil treatments $(p<0.05$, Tukey HSD).

Supplementary Table S3). Hence, the relative abundance (relative to 16S rRNA genes) of most of the tested genes was only detectable or considerably increased in bulk soil and rhizosphere after manure application. Accordingly, the tested ARGs as well as integrase genes were detected in the manure sample (Figure 1 and Supplementary Table S3). Lower relative abundances in the manure-treated rhizosphere than in the manure-treated bulk soil samples were observed for the genes $\operatorname{aad} A$, tet $(\mathrm{W})$, tet $(\mathrm{M})$, and tet $(\mathrm{Q})$, while no difference was observed between the 16S rRNA gene abundances (Figure 1 and 
Supplementary Table S3). Although there was a clear manure effect on the relative abundance of ARGs in the bulk soil and rhizosphere, no significant differences were detected between manure-treated soils and soils treated with doxycycline-spiked manure (Figure 1). Accordingly, only the relative abundance of the integrase gene intI1 in bulk soil showed a weak positive correlation with applied doxycycline concentrations (Pearson correlation coefficient $r=0.67, p<0.05$, Supplementary Tables S4, S5). However, significant correlations between target genes were observed in both bulk soil and rhizosphere. For instance, the positive correlations between tet(Q) and aadA $(r=0.75$ to 0.82$)$ and between qacE/qacE $\Delta 1$ and $a a d A$ ( $r=0.68$ to 0.83 ) were observed in both compartments, while the positive correlation between intI1 and tet(A) $(r=0.77, p<0.01)$ was only observed in bulk soil but not in the rhizosphere (Supplementary Tables S4, S5). Further differences in correlation coefficients between bulk soil and rhizosphere were observed for aadA and tet(A) as well as tet(W) and aadA.

For the lettuce phyllosphere, the absolute abundance of selected target genes, which were sampled from BS-C, BS-M, BSM-D50, and BS-M-D100, was determined. Most of the tested genes were not detected, with the exception of tet(A), which was

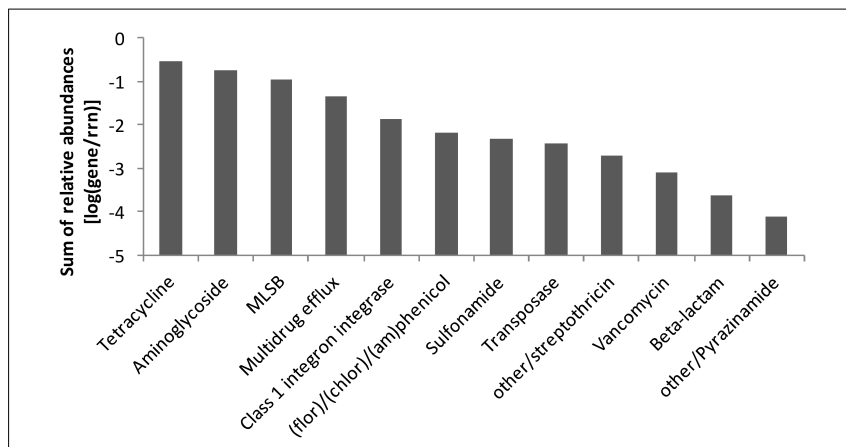

FIGURE 2 | Sum of relative abundances of genes [relative to 16S rRNA genes (rrn)] detected in the manure sample by high-throughput quantitative PCR (HT-qPCR). Genes were sorted by antibiotic and functional classes. present in TC-DNA of phyllosphere microbiota from BS-M, BSM-D50, and BS-M-D100 treatments. The average abundance of tet(A) ranged from 6.0 to $9.0 \log$ units (log10 gene copies per gram of leaves).

\section{High-Throughput Quantitative PCR Quantification of Antibiotic Resistance Genes and Mobile Genetic Elements in Bulk Soil, Rhizosphere, and Manure}

In manure, a total of 92 ARGs, MGEs, and class 1 integrons were detected. Tetracycline, aminoglycoside and macrolidelincosamide-streptogramin B (MLSB) resistance genes as well as multidrug efflux pump-encoding genes showed the highest abundances relative to $16 \mathrm{~S}$ rRNA genes (Figure 2). The tetracycline resistance genes with the highest proportion of total tetracycline resistance genes tested were tet $(\mathrm{M})$, $\operatorname{tet}(\mathrm{T}), \operatorname{tet} A(\mathrm{P})$, and tet $(\mathrm{Q})$ (Supplementary Figure S2). After manure application to soil, a total of 28 ARGs and the transposase gene tnpA were significantly enriched in BSM, BS-M-D100, and/or R-M-D100 compared to BS-C with tet $A(\mathrm{P})$, encoding a tetracycline efflux protein, showing the highest enrichment (Figure 3 and Supplementary Table S6). These genes conferred resistance against seven antibiotic classes, namely, aminoglycoside, beta-lactam, (fluoro)quinolone, tetracycline, MLSB, vancomycin, and (flor)/(chlor)amphenicol. Overall, the highest enrichments were observed for the classes of aminoglycoside and tetracycline resistance genes (Figure 4), which were also detected in a high relative abundance in the manure sample (Figure 2).

Furthermore, differences between the manure and doxycycline-spiked manure treatments were observed. In the BS-M, 18 genes were enriched compared to the BS-C. These genes were also detected in the manure sample. This number increased in the doxycycline-spiked manure treatments to 27 and 21 genes in TC-DNA samples from BS-M-D100 and R-M-D100, respectively. A total of 16 enriched genes were simultaneously detected in the BS-M, BS-M-D100, and R-M-D100, while five additional genes were only enriched in

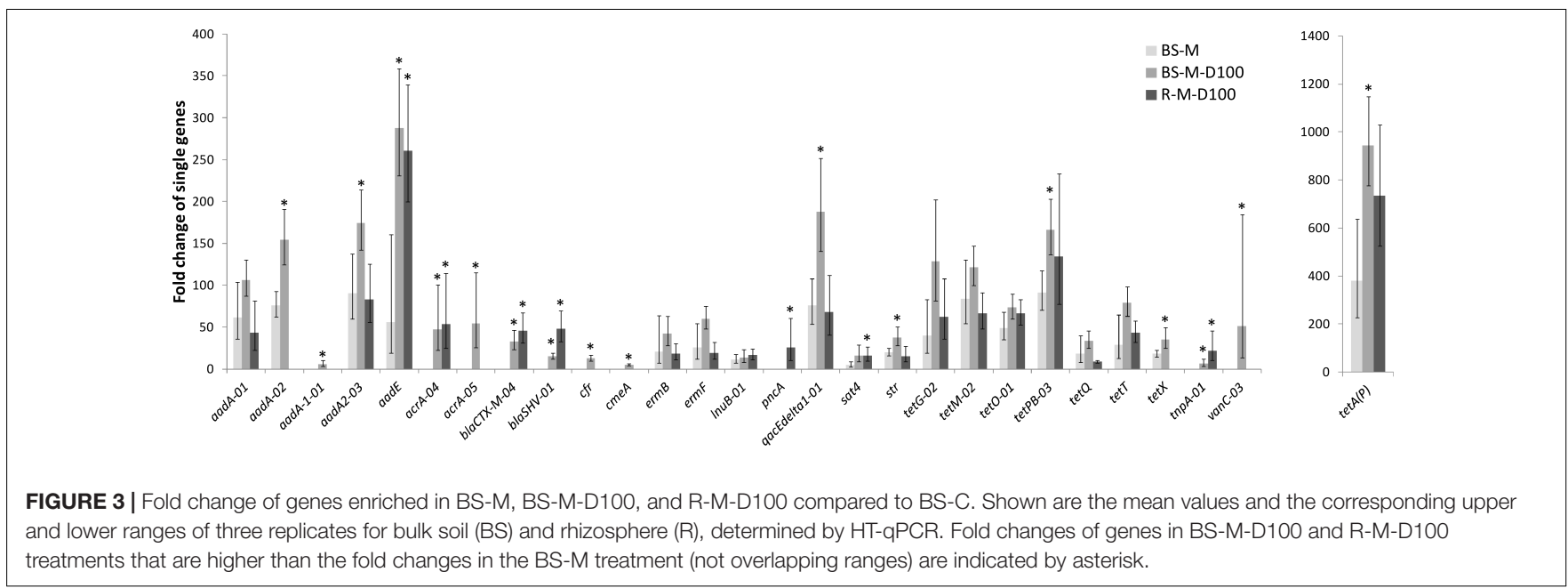




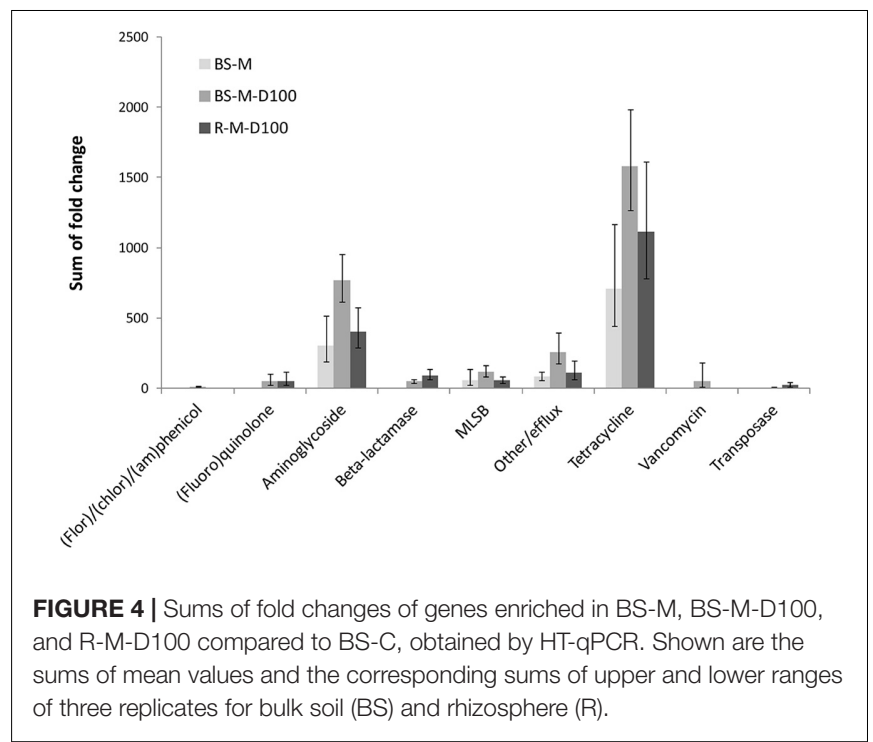

the BS-M-D100, one gene was detected only in the R-M-D100, and four genes were solely detected in both the BS-M-D100 and R-M-D100 (Figure 5).

In the BS-M-D100 treatment, the fold change of 17 genes was increased compared to BS-M (Supplementary Table S7). In the rhizosphere, this effect was smaller with only seven and two genes, which were increased and decreased in fold change compared to BS-M, respectively. Furthermore, comparing RHM-D100 to BS-M-D100, only two genes were higher in fold change, namely, bla SHV-01 $_{\text {and }}$ pncA, associated with betalactam and pyrazinamide resistance, respectively, while the majority of 15 genes had a lower fold change in RH-M-D100 compared to BS-M-D100.

\section{The Effects of Manure and Doxycycline Application on the Prokaryotic Community Composition in Bulk Soil and Rhizosphere}

The total number of quality filtered OTUs per replicate is given in Supplementary Table S2. Rarefaction analysis indicated that the obtained sequence numbers were sufficient to assess the prokaryotic diversity in the samples (Supplementary Figure S1). The relative abundances of sequences at the phylum and class levels are shown in Figure 6. In the manure sample, the most abundant class was Clostridia, which was also clearly increased in relative abundance in the BS-M and R-M compared to the BS-C and R-C. Proteobacteria and Actinobacteria were the two most dominant phyla in BS-C and R-C. Alpha-diversity indices showed that the prokaryotic community on day 42 in BS-C and R-C did not differ significantly regarding Shannon diversity index, Pielou's evenness, or Chao-1 species richness estimate (Supplementary Table S8). Furthermore, manure treatment (BS-M, R-M) did not significantly affect the diversity indices. However, in the BS-M-D100, R-M-D50, and R-M-D100 treatments, the Shannon and Pielou indices were significantly decreased compared to the untreated soils (BS-C and R-C). For the assessment of beta-diversity, the relative abundance of OTUs between samples was further compared by PCA. Here, distinct clusters were observed for BS-C, R-C, BS-M, and R-M (Figure 7).

The prokaryotic community compositions in bulk soil and rhizosphere were significantly different $(p=0.046)$, while the effect of the antibiotic treatment $(0,50$, and $100 \mathrm{mg}$ of doxycycline per kilogram of soil applied) was not significant ( $p=0.245$, Table 1). Furthermore, no significant interaction was observed between these two factors $(p=0.924)$.

For the $50 \mathrm{mg} \mathrm{kg}^{-1}$ doxycycline treatment, only three and two significant responders were detected in BS-M-D50

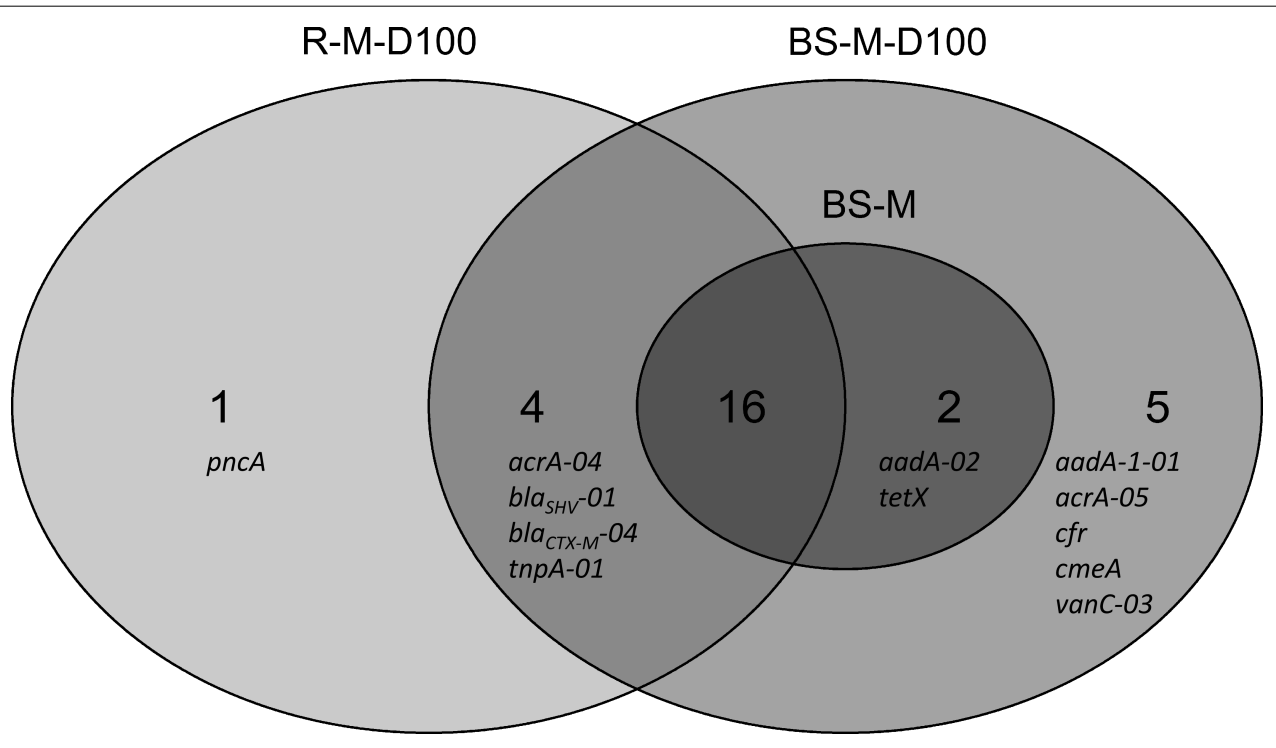

FIGURE 5 | Venn diagram distribution of genes that are enriched on day 42 in the manure and doxycycline-spiked manure treatments (BS-M, BS-M-D100, and R-M-D100) compared to the untreated soil (BS-C), obtained by HT-qPCR. 
A

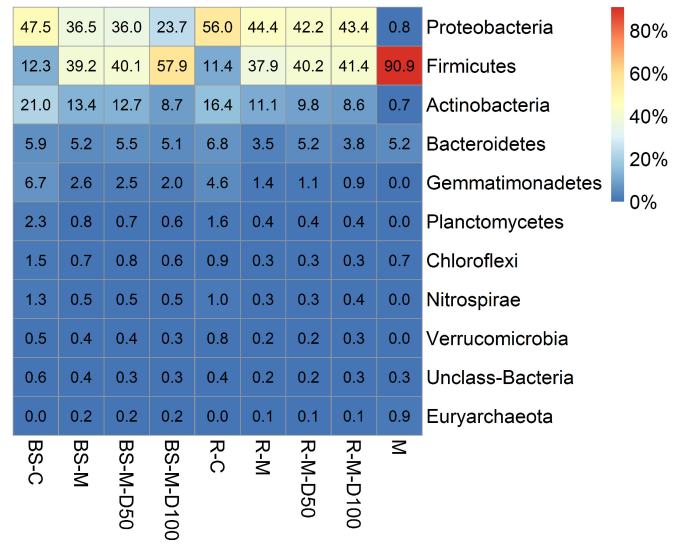

B

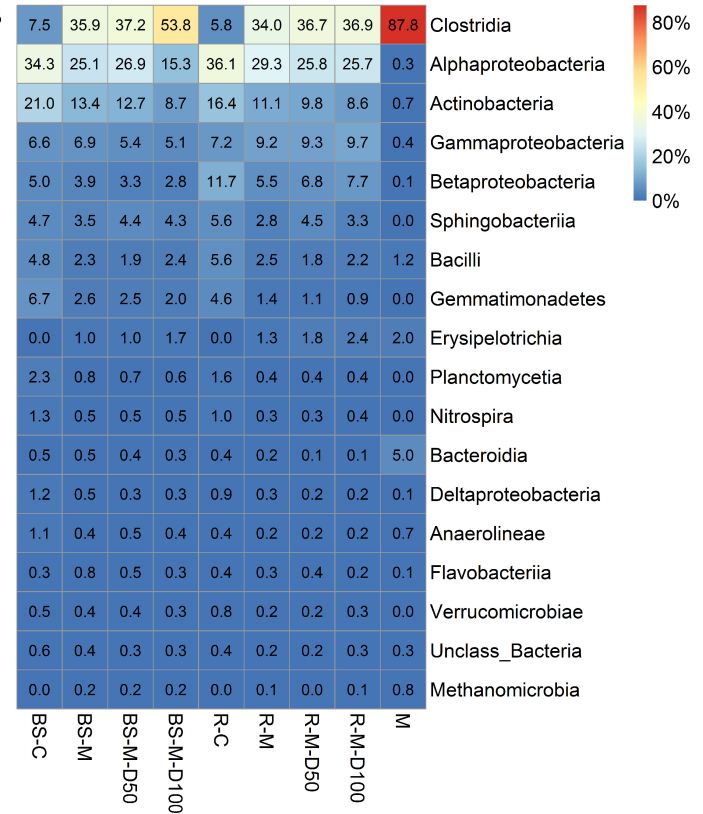

FIGURE 6 | Relative abundance of sequences (only if one value per row $>0.5 \%$ ) affiliated to prokaryotic phyla (A) and classes (B) for bulk soil $(B S)$, rhizosphere $(R)$, and manure $(M)$ is shown. Mean values for three replicate bulk soil or rhizosphere samples were calculated. The treatments manure (M), untreated control soil (C), and concentrations of 50 and $100 \mathrm{mg}$ doxycycline $\mathrm{kg}^{-1}$ dry soil (D50 and D100) are indicated.

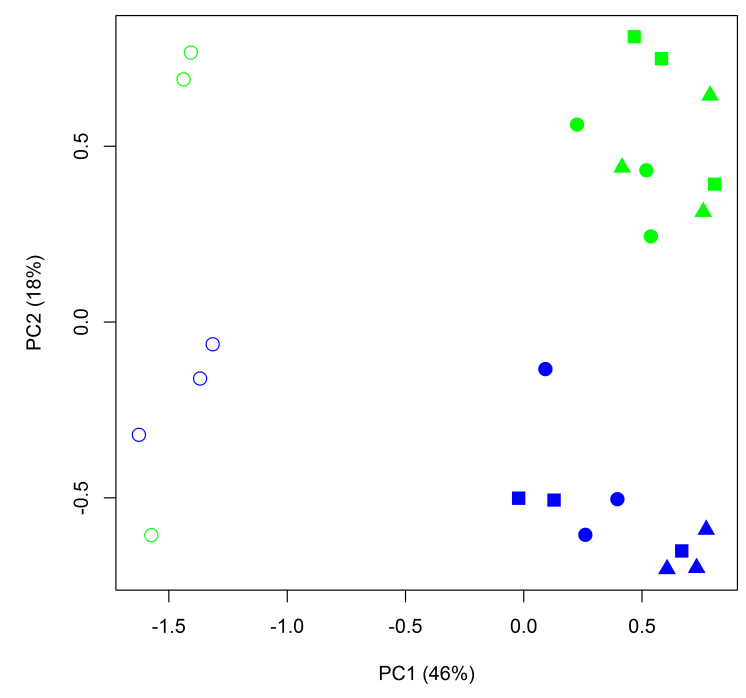

FIGURE 7 | Principal components analysis (PCA) on the log-transformed relative abundance of OTUs obtained from all bulk soil (blue) and rhizosphere (green) samples treated with and without manure (filled and open symbols, respectively), and spiked with doxycycline in low (squares) and high (triangles) concentration or without doxycycline (circles). Principal components (PCs) 1 and 2 explained 46 and $18 \%$ of the variance, respectively.

TABLE 1 | Effects of compartment (BS-M and R-M) and doxycycline application (D0, D50, and D100) on soil prokaryotic communities.

\begin{tabular}{lcc}
\hline Factor & Explained variance \% & $\boldsymbol{p}$-Value \\
\hline Compartment & $\mathbf{1 3 . 6 6}$ & $\mathbf{0 . 0 4 6}$ \\
Doxycycline & 14.33 & 0.242 \\
Compartment $\times$ Doxycycline & 5.13 & 0.927 \\
Residual sum & 66.88 &
\end{tabular}

PERMANOVA results are based on Bray-Curtis dissimilarities calculated with OTU counts (10,000 permutations). Bold numbers indicate significant differences $(p<0.05)$.

compared to BS-M. Some of these genera typically include opportunistic human and/or animal pathogens such as Legionella and Yersinia, which were detected in BS-M at low relative abundance (Table 2 and Supplementary Table S9).

\section{DISCUSSION}

and R-M-D50 compared to BS-M and R-M, respectively (Table 2). In the BS-M-D100 and R-M-D100 treatments, the number of significant responders compared to BS-M and R-M was increased with 12 and 6, respectively (Table 2). Genera that were enriched by doxycycline included Collimonas and Chitinophaga. The most abundant genera that were decreased in proportion were Rhizobium and Arthrobacter (Table 2). In $\mathrm{R}-\mathrm{M}$, nine genera were significantly enriched, and two genera were significantly decreased compared to BS-M (Supplementary Table S9). Enriched genera with the highest proportions were Legionella, Sphingobium, and Burkholderia, while Kineococcus and Owenweeksia were lower in relative abundance in the R-M

\section{Manure and Doxycycline Increased the Abundance of Antibiotic Resistance Genes and Mobile Genetic Elements in Bulk Soil}

Doxycycline, which is used against a wide range of infections with Gram-negative and Gram-positive bacteria, was frequently detected in manure that was applied as organic fertilizer to agricultural soils (Tylová et al., 2010; Carballo et al., 2016; van den Meersche et al., 2016; Widyasari-Mehta et al., 2016; Wolters et al., 2016; Albero et al., 2018). However, not much is known so far about the effects of doxycycline on the abundance of 


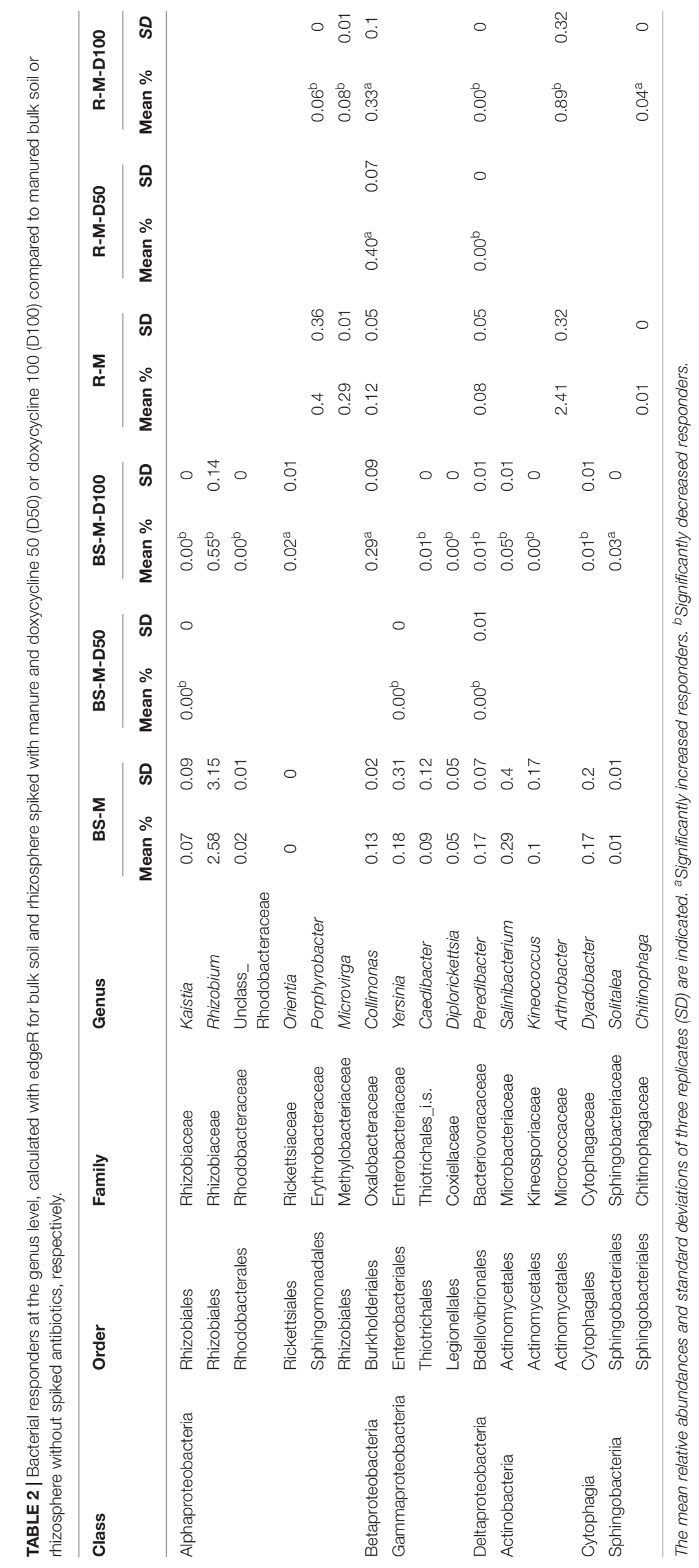


ARGs and MGEs as well as on the prokaryotic community structure in bulk soil and rhizosphere. In a previous study, we could already show that the application of manure, as well as of doxycycline-spiked manure, to agricultural soils was correlated with an increased relative abundance of ARGs and class 1 integrons. Furthermore, the soil bacterial community composition was affected over a period of 92 days, as revealed by DGGE of $16 \mathrm{~S}$ rRNA gene fragments amplified from TCDNA (Blau et al., 2017). Compared to manure, the effect of doxycycline was relatively minor and strongly dependent on the soil texture. However, in the study of Blau et al. (2017), only a limited set of ARGs and MGEs was selected to assess the effects of doxycycline on their relative abundance by TaqMan-based qPCR, together with analysis of the soil bacterial community composition.

In this study, the effect of doxycycline-spiked manure on the relative abundance of ARGs and MGEs, as well as on the prokaryotic community composition, was compared at high resolution between bulk soil and the rhizosphere of lettuce. Therefore, conventional quantification of a selection of 11 genes by TaqMan-based qPCR [genes were selected based on the preceding study of Blau et al. (2017)] was compared to HT-qPCR including 296 genes and combined with Illumina sequencing of $16 \mathrm{~S}$ rRNA gene amplicons. The application of manure alone drastically increased the abundance of ARGs in bulk soil and rhizosphere as revealed by the qPCR and HT-qPCR assays, confirming the results of previous studies demonstrating an effect of manure application on ARG and MGE abundance in soil (Heuer et al., 2011a; Jechalke et al., 2013b; Hu et al., 2016; Blau et al., 2017; Chen et al., 2017; Zhang et al., 2017; Wolters et al., 2018). The results obtained by TaqMan-based qPCR were in agreement with the HT-qPCR data, both showing a significant increase of $q a c E / q a c E \Delta 1, \operatorname{tet}(\mathrm{Q})$, tet(M), and aadA in BS-M compared to BS-C, while additionally tet(A) and tet(W) were not detected in BS-C but detectable by TaqMan qPCR in BS-M. However, it has to be mentioned that tet(W) was not included in the HT-qPCR assay and different primer systems for tet(A) were used for the two approaches. The HT-qPCR data showed that mainly tetracycline and aminoglycoside resistance as well as efflux pump-related genes were enriched in BS-M compared to the BS-C. This confirms the results of previous studies demonstrating that the most dominant ARG types in pig manure were tetracycline, aminoglycoside, and MLSB resistance (Zhao et al., 2017; Fang et al., 2018). Likely, one reason for this high abundance of ARGs in pig manure is the presence of infeed antibiotics and heavy metals that was correlated with ARGs detected in pig gut microbiota (Zhao et al., 2017).

No additional doxycycline effect was observed by TaqManbased $\mathrm{qPCR}$ in soils treated with doxycycline-spiked manure compared to manure-treated soils. Only the relative abundance of the integrase gene intI1 in bulk soil showed a weak positive correlation with applied doxycycline concentrations. In contrast, a clear effect of the doxycycline treatment was observed by HT-qPCR showing that 17 genes were highly enriched in the BSM-D100 compared to the BS-M treatment. Importantly, these genes included not only tetracycline resistance genes that were not tested by the TaqMan-based qPCR but also genes conferring resistance to other antibiotic classes as well as the transposonrelated gene $\operatorname{tn} p A$. These results confirm the results obtained by Blau et al. (2017), showing that doxycycline applied via manure to soil is bioavailable and can select and co-select for ARGs and MGEs in soil bacterial communities. Interestingly, no significant effect of manure or doxycycline-spiked manure application on the abundance of intI1 genes was observed in this study. We hypothesize that 42 days after application, the effect on intI1 gene abundance in soil decreased to control levels due to a decrease in manure-derived bacterial populations carrying class 1 integrons over time and due to a decrease in bioavailable concentrations of doxycycline, reducing the selective pressure on soil bacterial communities. This is supported by the study of Blau et al. (2017), observing a lower relative abundance of intI1 in soil on day 92 compared to day 28 after manure application. Recently, Yan et al. (2018) observed that soil amendment with manure from doxycycline-treated pigs, allowing antibiotic selection already in the animal, increased the number of tetracycline resistance genes tet(A), tet $(\mathrm{M})$, tet $(\mathrm{W})$, and tet $(\mathrm{X})$, but not tet $(\mathrm{G})$, which was confirmed in this study for tet $(\mathrm{X})$ and $\operatorname{tet}(\mathrm{G})$. Furthermore, the results of the present study demonstrated that the effects of doxycycline entering the soil via manure might be underestimated if only a limited selection of genes is considered in the environmental risk assessment.

\section{Less Pronounced Effects of Manure and Doxycycline on Antibiotic Resistance Genes and Mobile Genetic Elements in the Rhizosphere of Lettuce}

The rhizosphere is regarded as a hotspot of microbial activity and HGT, which might alter the fate and effects of doxycycline in agricultural soils (Rosendahl et al., 2011; Jechalke et al., 2013a,b; Chen et al., 2018). HT-qPCR revealed that the effect of doxycycline-spiked manure on the number of enriched genes and on the fold change of enrichment was less pronounced in the rhizosphere than in bulk soil. This is in agreement with results of previous studies demonstrating smaller effects of antibiotics applied with manure in the rhizosphere (Jechalke et al., 2013a,b; Kopmann et al., 2013; Wang et al., 2015; Kang et al., 2017; Chen et al., 2018). The reduced effect might be related to an accelerated dissipation of doxycycline in the rhizosphere due to plantenhanced microbial biotransformation processes, as suggested previously for different antibiotics (Rosendahl et al., 2012; Chen et al., 2018). Evidence that the soil microbiome can be involved in doxycycline degradation was given by Yan et al. (2018). However, it cannot be excluded that a higher population density and competition in the rhizosphere buffered the effect of manure and doxycycline application on the abundance of ARGs relative to $16 \mathrm{~S}$ rRNA gene abundance and decreased the persistence of manure-derived bacteria. This is supported by TaqManbased qPCR showing lower relative abundances of aadA, tet (W), tet $(\mathrm{M})$, and tet $(\mathrm{Q})$ in $\mathrm{R}-\mathrm{M}$ than in $\mathrm{BS}-\mathrm{M}$ soil, demonstrating that the smaller effects of doxycycline observed in the rhizosphere are at least partly due to reduced effects of manure on ARG abundance. In contrast, the enrichments of beta-lactam (bla) 
resistance genes, pyrazinamide resistance-associated genes, and transposase genes were similar (bla $a_{\mathrm{CTX}-\mathrm{M}}$ and $\left.\operatorname{tn} p A\right)$ or increased (bla $a_{\mathrm{SHV}}$ and $p n c A$ ) in R-M-D100 compared to BS-M-D100. This might suggest that indigenous rhizosphere bacteria carrying bla and $p n c A$ genes might have benefited from manure-derived nutrients and the application of doxycycline. Accordingly, CTX$\mathrm{M}$ enzymes were described to originate in Kluyvera spp., which normally inhabit the rhizosphere (Humeniuk et al., 2002; Bevan et al., 2017).

\section{Distribution of Antibiotic Resistance Genes in the Lettuce Phyllosphere}

In TC-DNA obtained from the lettuce phyllosphere, all genes tested by TaqMan-based qPCR, except for tet(A), were not detected. This was surprising since previous studies detected ARGs on harvested vegetables grown in soil that was treated with manure or sewage sludge (Marti et al., 2013; Wang et al., 2015; Rahube et al., 2016; Tien et al., 2017). Leaves of field-grown lettuce are exposed to a high number of bacteria originating from dust and soil particles transported by wind and from irrigation water or rainwater, which could already contain bacteria or transfer soil particles to the leaves by splash erosion. Furthermore, bacteria may be transported to crops on-field by different shuttles like insects, livestock, birds, wild animals, and agricultural equipment (Alegbeleye et al., 2018). In the present greenhouse study, it is likely that the phyllosphere did not harbor dense leaf-associated bacterial populations due to controlled conditions, which might explain the low number of ARGs and MGEs detected by qPCR. Therefore, ARGs in the phyllosphere were not analyzed by HT-qPCR. However, tet(A) was detected in bacteria from lettuce leaves but only from the manure treatments. This is in agreement with the results of a previous study detecting tet(A) in bacteria from the phyllosphere of lettuce grown on manure-amended soil (Wang et al., 2015).

\section{Manure and Doxycycline Application Affect the Soil Prokaryotic Community Composition}

The Illumina sequencing results showed that Actinobacteria and Proteobacteria were the most dominant phyla in BS-C and R-C. Their proportion was highly decreased after manure application. These findings were consistent with several previous studies also reporting a decrease of Actinobacteria after application of organic amendment (Calleja-Cervantes et al., 2015; Liu et al., 2017). At the same time, we observed that manure application increased the proportion of Firmicutes (Clostridia) in bulk soil and lettuce rhizosphere, which was expected regarding the high proportion of Clostridia in manure. This is in line with previous studies demonstrating a high proportion of Clostridia in manure as well as a clear effect on soil bacterial communities (Ding et al., 2014; Jechalke et al., 2014). Leclercq et al. (2016) observed that members of the gut microbiota such as Clostridium spp. as well as environmental Pseudomonas spp. and Acinetobacter spp. were responsible for the persistence of ARGs in manure-amended soils. Furthermore, several previous studies reported that Firmicutes, Proteobacteria, Bacteroidetes, and Actinobacteria represent the dominant phyla in manure and manure-amended soils (Shen et al., 2010; Zhang et al., 2013; Sun et al., 2014; Johnson et al., 2016; Yang et al., 2016; Yan et al., 2018). It was shown that ARGs and in particular tetracycline resistance mechanisms were prevalent in Firmicutes, Proteobacteria, Bacteroidetes, and Actinobacteria (Gibson et al., 2015; Kang et al., 2018), which is in agreement with the observed enrichment of tetracycline resistance genes in manure-treated soils in this study. Interestingly, the tetracycline resistance gene tet $A(\mathrm{P})$ was highly enriched in the manure-treated soils and even higher in doxycycline-treated BS-M-D100. This enrichment of the $\operatorname{tet} A(\mathrm{P})$ gene might have been connected to the enrichment of Clostridia in the manure-amended soil, as this gene was first described in Clostridium perfringens (Sloan et al., 1994). Furthermore, these results demonstrate that the $\operatorname{tet} A(\mathrm{P})$ gene might be a suitable marker for the contamination of soil by ARB, ARGs, and antibiotics originated from manure application.

At the genus level, a clear effect of doxycycline on the prokaryotic soil community was observed that increased with doxycycline concentration. While in BS-M-D50 and R-M-D50 treatments, only three and two responders were identified compared to the BS-M and R-M treatments, respectively, these numbers increased in the BS-M-D100 and R-M-D100 treatments to 12 and 6 responders, respectively. This is in line with the observed reduction in richness and evenness in BS-M-D100, R-M-D50, and R-M-D100 compared to the untreated soils (BS$\mathrm{C}$ and $\mathrm{R}-\mathrm{C}$ ), showing that the evenness of the community was altered due to the increased dominance of some members. A similar doxycycline-concentration-dependent effect on the microbial community composition was observed recently by Yan et al. (2018), applying manure from doxycycline-treated pigs to soil. In agreement with the qPCR data, a smaller number of responders were observed in the rhizosphere, indicating a less pronounced effect of doxycycline on the rhizosphere prokaryotic community. Interestingly, Collimonas and Chitinophaga were enriched in BS-M-D100, R-M-D50, and R-M-D100. These genera were described to harbor genes encoding degradative enzymes (e.g., chitinase) and secondary metabolites important for interaction with fungi, since these genera have the ability to grow in or on living fungal hyphae (Boer et al., 2004; Song et al., 2015; Shaffer et al., 2017). Therefore, we speculate that an increase in these genera in soil might have been caused by the enrichment of fungal communities, benefiting from the application of doxycycline reducing the number of bacteria competing for nutrients and environmental niches. This would agree with the results of Yan et al. (2018) who observed that the abundance of soil bacteria decreased while the abundance of fungi increased with higher doxycycline concentration. Additionally, genera associated with opportunistic human or animal pathogens, such as Yersinia and Legionella, were detected in manured soil, which is in line with previous studies (Hong et al., 2013). Rhizobium was among the genera that were reduced in abundance in BS-M-D100 compared to BS-M. Some strains belonging to this genus are known to carry nif genes involved in the fixation of nitrogen (Shamseldin, 2013), indicating a potential negative effect of doxycycline application on nitrogen fixation of plants. 


\section{CONCLUSION}

The study revealed that the application of manure and manure spiked with doxycycline had a strong impact on the abundance and diversity of ARGs, MGEs, and the prokaryotic community structure, which was more pronounced in the bulk soil than in the rhizosphere of lettuce. This implies that the plant has an important role in modulating the effects and fate of manure-derived antibiotics and ARB, likely via the microbes selected in its rhizosphere by root exudation. Manure application led to a decreased relative abundance of Proteobacteria and Actinobacteria in bulk soil and rhizosphere, while that of Firmicutes increased. Interestingly, the tetracycline resistance gene tet $A(\mathrm{P})$ was highly enriched in the manuretreated bulk soil and rhizosphere and highest in BS-M-D100, which might be connected to the increase in Clostridia. These findings demonstrate that the gene tet $A(\mathrm{P})$ might be a suitable marker for the contamination of soil by ARB, ARGs, and antibiotics originated from manure application. Collimonas and Chitinophaga were enriched in the doxycycline treatment, probably associated with an enrichment of fungal communities, which might have benefited from the reduction of bacterial competitors due to the antibiotic treatment applied. The study provided novel insights into the effects of manure containing doxycycline on the bacterial community composition as well as on the abundance of ARGs and MGEs in bulk soil and rhizosphere of lettuce. However, further studies are needed to

\section{REFERENCES}

Albero, B., Tadeo, J. L., Escario, M., Miguel, E., and Pérez, R. A. (2018). Persistence and availability of veterinary antibiotics in soil and soil-manure systems. Sci. Total Environ. 643, 1562-1570. doi: 10.1016/j.scitotenv.2018. 06.314

Alegbeleye, O. O., Singleton, I., and Sant'Ana, A. S. (2018). Sources and contamination routes of microbial pathogens to fresh produce during field cultivation: a review. Food Microbiol. 73, 177-208. doi: 10.1016/j.fm.2018. 01.003

Alexander, T. W., Jin, X., Li, Q., Cook, S., and McAllister, T. A. (2013). Characterization of tetracycline resistance genes in Escherichia coli isolated from feedlot cattle administered therapeutic or subtherapeutic levels of tetracycline. Can. J. Microbiol. 59, 287-290. doi: 10.1139/cjm2012-0660

Arikan, O. A., Sikora, L. J., Mulbry, W., Khan, S. U., and Foster, G. D. (2007). Composting rapidly reduces levels of extractable oxytetracycline in manure from therapeutically treated beef calves. Bioresour. Technol. 98, 169-176. doi: 10.1016/j.biortech.2005.10.041

Aust, M. O., Thiele-Bruhn, S., Eckhardt, K. U., and Leinweber, P. (2009). Composition of organic matter in particle size fractionated pig slurry. Bioresour. Technol. 100, 5736-5743. doi: 10.1016/j.biortech.2009. 06.065

Babin, D., Deubel, A., Jacquiod, S., Sørensen, S. J., Geistlinger, J., Grosch, R., et al. (2018). Impact of long-term agricultural management practices on soil prokaryotic communities. Soil Biol. Biochem. 129, 17-28. doi: 10.1016/j.soilbio. 2018.11.002

Bevan, E. R., Jones, A. M., and Hawkey, P. M. (2017). Global epidemiology of CTX$\mathrm{M}$ beta-lactamases: temporal and geographical shifts in genotype. J. Antimicrob. Chemother. 72, 2145-2155. doi: 10.1093/jac/dkx146

Binh, C. T., Heuer, H., Kaupenjohann, M., and Smalla, K. (2009). Diverse aadA gene cassettes on class 1 integrons introduced into soil via spread manure. Res. Microbiol. 160, 427-433. doi: 10.1016/j.resmic.2009.06.005 explore the potential transfer of ARGs and ARB from manure and manured soil to crops and associated risks for human health.

\section{AUTHOR CONTRIBUTIONS}

$\mathrm{KB}, \mathrm{KS}$, and SJe are responsible for research design and concept and wrote the manuscript with contributions of all co-authors. $\mathrm{KB}$ and SJe performed the experiments and laboratory work and performed and analyzed the qPCR (TaqMan). SJa and SS performed the Illumina sequencing and processing. SJe, J-QS, and Y-GZ performed the HT-qPCR. SJe analyzed the Illumina sequences and HT-qPCR data.

\section{FUNDING}

$\mathrm{KB}$ was funded by the Libyan Government. SJe was funded by the German Environmental Agency (Umweltbundesamt) (FKZ 371363 402).

\section{SUPPLEMENTARY MATERIAL}

The Supplementary Material for this article can be found online at: https://www.frontiersin.org/articles/10.3389/fmicb. 2019.00725/full\#supplementary-material

Blau, K., Casadevall, L., Wolters, B., van den Meersche, T., Kreuzig, R., Smalla, K., et al. (2017). Soil texture-depending effects of doxycycline and streptomycin applied with manure on the bacterial community composition and resistome. FEMS Microbiol. Ecol. 94:fix145. doi: 10.1093/femsec/fix145

Boer, W., Leveau, J. H. J., Kowalchuk, G. A., Klein Gunnewiek, P. J. A., Abeln, E. C. A., Figge, M. J., et al. (2004). Collimonas fungivorans gen. nov., sp. nov., a chitinolytic soil bacterium with the ability to grow on living fungal hyphae. Int. J. Syst. Evol. Microbiol. 54, 857-864. doi: 10.1099/ijs.0.02920-0

Calleja-Cervantes, M. E., Menéndez, S., Fernández-González, A. J., Irigoyen, I., Cibriáin-Sabalza, J. F., Toro, N., et al. (2015). Changes in soil nutrient content and bacterial community after 12 years of organic amendment application to a vineyard. Eur. J. Soil Sci. 66, 802-812. doi: 10.1111/ejss.12261

Caporaso, J. G., Bittinger, K., Bushman, F. D., DeSantis, T. Z., Andersen, G. L., and Knight, R. (2010a). PyNAST: a flexible tool for aligning sequences to a template alignment. Bioinformatics 26, 266-267. doi: 10.1093/bioinformatics/ btp636

Caporaso, J. G., Kuczynski, J., Stombaugh, J., Bittinger, K., Bushman, F. D., Costello, E. K., et al. (2010b). QIIME allows analysis of high-throughput community sequencing data. Nat. Methods 7, 335-336. doi: 10.1038/nmeth. f.303

Carballo, M., Aguayo, S., González, M., Esperon, F., and La Torre, A. D. (2016). Environmental assessment of tetracycline's residues detected in pig slurry and poultry manure. JEP 07, 82-92. doi: 10.4236/jep.2016.71008

Chee-Sanford, J. C., Aminov, R. I., Krapac, I. J., Garrigues-Jeanjean, N., and Mackie, R. I. (2001). Occurrence and diversity of tetracycline resistance genes in lagoons and groundwater underlying two swine production facilities. Appl. Environ. Microbiol. 67, 1494-1502. doi: 10.1128/AEM.67.4.1494-1502.2001

Chee-Sanford, J. C., Mackie, R. I., Koike, S., Krapac, I. G., Lin, Y. F., Yannarell, A. C., et al. (2009). Fate and transport of antibiotic residues and antibiotic resistance genes following land application of manure waste. J. Environ. Qual. 38, 1086-1108. doi: 10.2134/jeq2008.0128

Chen, C., Guron, G. K., Pruden, A., Ponder, M., Du, P., and Xia, K. (2018). Antibiotics and antibiotic resistance genes in bulk and rhizosphere soils subject 
to manure amendment and vegetable cultivation. J. Environ. Qual. 47:1318. doi: 10.2134/jeq2018.02.0078

Chen, Q.-L., An, X.-L., Li, H., Zhu, Y.-G., Su, J.-Q., and Cui, L. (2017). Do manureborne or indigenous soil microorganisms influence the spread of antibiotic resistance genes in manured soil? Soil Biol. Biochem. 114, 229-237. doi: 10.1016/ j.soilbio.2017.07.022

Chopra, I., and Roberts, M. (2001). Tetracycline antibiotics: mode of action, applications, molecular biology, and epidemiology of bacterial resistance. Microbiol. Mol. Biol. Rev. 65, 232-260. doi: 10.1128/mmbr.65.2.232-260.2001

DeSantis, T. Z., Hugenholtz, P., Larsen, N., Rojas, M., Brodie, E. L., Keller, K., et al. (2006). Greengenes, a chimera-checked 16S rRNA gene database and workbench compatible with ARB. Appl. Environ. Microbiol. 72, 5069-5072. doi: 10.1128/AEM.03006-05

Ding, G. C., Radl, V., Schloter-Hai, B., Jechalke, S., Heuer, H., Smalla, K., et al. (2014). Dynamics of soil bacterial communities in response to repeated application of manure containing sulfadiazine. PLoS One 9:e92958. doi: 10. 1371/journal.pone.0092958

Edgar, R. C. (2010). Search and clustering orders of magnitude faster than BLAST. Bioinformatics 26, 2460-2461. doi: 10.1093/bioinformatics/btq461

Edgar, R. C. (2013). UPARSE: highly accurate OTU sequences from microbial amplicon reads. Nat. Methods 10, 996-998. doi: 10.1038/nmeth.2604

Fang, H., Han, L., Zhang, H., Long, Z., Cai, L., and Yu, Y. (2018). Dissemination of antibiotic resistance genes and human pathogenic bacteria from a pig feedlot to the surrounding stream and agricultural soils. J. Hazard. Mater. 357, 53-62. doi: 10.1016/j.jhazmat.2018.05.066

Ghosh, S., and LaPara, T. M. (2007). The effects of subtherapeutic antibiotic use in farm animals on the proliferation and persistence of antibiotic resistance among soil bacteria. ISME J. 1, 191-203. doi: 10.1038/ismej.2007.31

Gibson, M. K., Forsberg, K. J., and Dantas, G. (2015). Improved annotation of antibiotic resistance determinants reveals microbial resistomes cluster by ecology. ISME J. 9, 207-216. doi: 10.1038/ismej.2014.106

Gullberg, E., Cao, S., Berg, O. G., Ilback, C., Sandegren, L., Hughes, D., et al. (2011). Selection of resistant bacteria at very low antibiotic concentrations. PLoS Pathog. 7:e1002158. doi: 10.1371/journal.ppat.1002158

Haack, B. J., and Andrews, R. E. (2000). Isolation of Tn916-like conjugal elements from swine lot effluent. Can. J. Microbiol. 46, 542-549. doi: 10.1139/w00-029

Haas, B. J., Gevers, D., Earl, A. M., Feldgarden, M., Ward, D. V., Giannoukos, G., et al. (2011). Chimeric 16S rRNA sequence formation and detection in Sanger and 454-pyrosequenced PCR amplicons. Genome Res. 21, 494-504. doi: 10.1101/gr.112730.110

Heuer, H., Focks, A., Lamshöft, M., Smalla, K., Matthies, M., and Spiteller, M. (2008). Fate of sulfadiazine administered to pigs and its quantitative effect on the dynamics of bacterial resistance genes in manure and manured soil. Soil Biol. Biochem. 40, 1892-1900. doi: 10.1016/j.soilbio.2008. 03.014

Heuer, H., and Smalla, K. (2007). Manure and sulfadiazine synergistically increased bacterial antibiotic resistance in soil over at least two months. Environ. Microbiol. 9, 657-666. doi: 10.1111/j.1462-2920.2006. 01185.x

Heuer, H., Schmitt, H., and Smalla, K. (2011a). Antibiotic resistance gene spread due to manure application on agricultural fields. Curr. Opin. Microbiol. 14, 236-243. doi: 10.1016/j.mib.2011.04.009

Heuer, H., Solehati, Q., Zimmerling, U., Kleineidam, K., Schloter, M., Müller, T., et al. (2011b). Accumulation of sulfonamide resistance genes in arable soils due to repeated application of manure containing sulfadiazine. Appl. Environ. Microbiol. 77, 2527-2530. doi: 10.1128/AEM.02577-10

Heuer, H., and Smalla, K. (2012). Plasmids foster diversification and adaptation of bacterial populations in soil. FEMS Microbiol. Rev. 36, 1083-1104. doi: 10.1111/ j.1574-6976.2012.00337.x

Hong, P.-Y., Yannarell, A. C., Dai, Q., Ekizoglu, M., and Mackie, R. I. (2013). Monitoring the perturbation of soil and groundwater microbial communities due to pig production activities. Appl. Environ. Microbiol. 79, 2620-2629. doi: 10.1128/AEM.03760-12

Hu, H. W., Han, X. M., Shi, X. Z., Wang, J. T., Han, L. L., Chen, D., et al. (2016). Temporal changes of antibiotic-resistance genes and bacterial communities in two contrasting soils treated with cattle manure. FEMS Microbiol. Ecol. 92:fiv169. doi: 10.1093/femsec/fiv169
Humeniuk, C., Arlet, G., Gautier, V., Grimont, P., Labia, R., and Philippon, A. (2002). $\beta$-Lactamases of Kluyvera ascorbata, probable progenitors of some plasmid-encoded CTX-M types. Antimicrob. Agents Chemother. 46, 3045-3049. doi: 10.1128/AAC.46.9.3045-3049.2002

Jacquiod, S., Brejnrod, A., Morberg, S. M., Abu Al-Soud, W., Sørensen, S. J., and Riber, L. (2017). Deciphering conjugative plasmid permissiveness in wastewater microbiomes. Mol. Ecol. 26, 3556-3571. doi: 10.1111/mec.14138

Jechalke, S., Focks, A., Rosendahl, I., Groeneweg, J., Siemens, J., Heuer, H., et al. (2013a). Structural and functional response of the soil bacterial community to application of manure from difloxacin-treated pigs. FEMS Microbiol. Ecol. 87, 78-88. doi: 10.1111/1574-6941.12191

Jechalke, S., Kopmann, C., Rosendahl, I., Groeneweg, J., Weichelt, V., Krögerrecklenfort, E., et al. (2013b). Increased abundance and transferability of resistance genes after field application of manure from sulfadiazine-treated pigs. Appl. Environ. Microbiol. 79, 1704-1711. doi: 10.1128/aem.03172-12

Jechalke, S., Heuer, H., Siemens, J., Amelung, W., and Smalla, K. (2014). Fate and effects of veterinary antibiotics in soil. Trends Microbiol. 22, 536-545. doi: 10.1016/j.tim.2014.05.005

Johnson, T. A., Stedtfeld, R. D., Wang, Q., Cole, J. R., Hashsham, S. A., Looft, T., et al. (2016). Clusters of antibiotic resistance genes enriched together stay together in swine agriculture. MBio 7:e2214-15. doi: 10.1128/mBio.02214-15

Kang, Y., Hao, Y., Xia, D., Shen, M., Li, Q., and Hu, J. (2017). The effects of pig manure application on the spread of tetracycline resistance in bulk and cucumber rhizosphere soils: a greenhouse experiment. Can. J. Microbiol. 63, 563-572. doi: 10.1139/cjm-2016-0767

Kang, Y., Li, Q., Yin, Z., Shen, M., Zhao, H., Bai, Y., et al. (2018). High diversity and abundance of cultivable tetracycline-resistant bacteria in soil following pig manure application. Sci. Rep. 8:1489. doi: 10.1038/s41598-018-20050-8

Klode, R. (2019). Pheatmap: Pretty Heatmaps. R Package Version 1.0.12. Avaialable at: https://rdrr.io/cran/pheatmap/ (accessed January 4, 2019).

Kopmann, C., Jechalke, S., Rosendahl, I., Groeneweg, J., Krögerrecklenfort, E., Zimmerling, U., et al. (2013). Abundance and transferability of antibiotic resistance as related to the fate of sulfadiazine in maize rhizosphere and bulk soil. FEMS Microbiol. Ecol. 83, 125-134. doi: 10.1111/j.1574-6941.2012.01458.x

Leclercq, S. O., Wang, C., Sui, Z., Wu, H., Zhu, B., Deng, Y., et al. (2016). A multiplayer game: species of Clostridium, Acinetobacter, and Pseudomonas are responsible for the persistence of antibiotic resistance genes in manuretreated soils. Environ. Microbiol. 18, 3494-3508. doi: 10.1111/1462-2920.13337

Liu, P., Jia, S., He, X., Zhang, X., and Ye, L. (2017). Different impacts of manure and chemical fertilizers on bacterial community structure and antibiotic resistance genes in arable soils. Chemosphere 188, 455-464. doi: 10.1016/j.chemosphere. 2017.08.162

Looft, T., Johnson, T. A., Allen, H. K., Bayles, D. O., Alt, D. P., Stedtfeld, R. D., et al. (2012). In-feed antibiotic effects on the swine intestinal microbiome. Proc. Natl. Acad. Sci. U.S.A. 109, 1691-1696. doi: 10.1073/pnas.1120238109

Marti, R., Scott, A., Tien, Y. C., Murray, R., Sabourin, L., Zhang, Y., et al. (2013). Impact of manure fertilization on the abundance of antibiotic-resistant bacteria and frequency of detection of antibiotic resistance genes in soil and on vegetables at harvest. Appl. Environ. Microbiol. 79, 5701-5709. doi: 10.1128/ aem.01682-13

McCarthy, D. J., Chen, Y., and Smyth, G. K. (2012). Differential expression analysis of multifactor RNA-Seq experiments with respect to biological variation. Nucleic Acids Res. 40, 4288-4297. doi: 10.1093/nar/gks042

Mølbak, L., Molin, S., and Kroer, N. (2007). Root growth and exudate production define the frequency of horizontal plasmid transfer in the rhizosphere. FEMS Microbiol. Ecol. 59, 167-176. doi: 10.1111/j.1574-6941.2006. 00229.x

Nunes, I., Jacquiod, S., Brejnrod, A., Holm, P. E., Johansen, A., Brandt, K. K., et al. (2016). Coping with copper: legacy effect of copper on potential activity of soil bacteria following a century of exposure. FEMS Microbiol. Ecol. 92:fiw175. doi: $10.1093 /$ femsec/fiw 175

Oksanen, J., Blanchet, F. G., Friendly, M., Kindt, R., Legendre, P., McGlinn, D., et al. (2018). Community Ecology Package: R package version 2.5-3. Available at: https://CRAN.R-project.org/package = vegan $($ accessed February 4, 2019).

Ouyang, W.-Y., Huang, F.-Y., Zhao, Y., Li, H., and Su, J.-Q. (2015). Increased levels of antibiotic resistance in urban stream of Jiulongjiang River. China. Appl. Microbiol. Biotechnol. 99, 5697-5707. doi: 10.1007/s00253-015-6416-5 
Price, M. N., Dehal, P. S., and Arkin, A. P. (2010). FastTree 2-approximately maximum-likelihood trees for large alignments. PLoS One 5:e9490. doi: 10.1371/journal.pone. 0009490

Rahube, T. O., Marti, R., Scott, A., Tien, Y. C., Murray, R., Sabourin, L., et al. (2016). Persistence of antibiotic resistance and plasmid-associated genes in soil following application of sewage sludge and abundance on vegetables at harvest. Can. J. Microbiol. 62, 600-607. doi: 10.1139/cjm-2016-0034

Roberts, D. (2016). Labdsv: Ordination and Multivariate Analysis for Ecology. $R$ Package Version 1.8-0. Available at: https://CRAN.R-project.org/package $=$ labdsv (accessed January 24, 2016).

Robinson, M. D., McCarthy, D. J., and Smyth, G. K. (2010). edgeR: a bioconductor package for differential expression analysis of digital gene expression data. Bioinformatics 26, 139-140. doi: 10.1093/bioinformatics/btp616

Rosendahl, I., Siemens, J., Groeneweg, J., Linzbach, E., Laabs, V., Herrmann, C., et al. (2011). Dissipation and sequestration of the veterinary antibiotic sulfadiazine and its metabolites under field conditions. Environ. Sci. Technol. 45, 5216-5222. doi: 10.1021/es200326t

Rosendahl, I., Siemens, J., Kindler, R., Groeneweg, J., Zimmermann, J., Czerwinski, S., et al. (2012). Persistence of the fluoroquinolone antibiotic difloxacin in soil and lacking effects on nitrogen turnover. J. Environ. Qual. 41, 1275-1283. doi: 10.2134/jeq2011.0459

Sarmah, A. K., Meyer, M. T., and Boxall, A. B. (2006). A global perspective on the use, sales, exposure pathways, occurrence, fate and effects of veterinary antibiotics (VAs) in the environment. Chemosphere 65, 725-759. doi: 10.1016/j. chemosphere.2006.03.026

Schloss, P. D., Westcott, S. L., Ryabin, T., Hall, J. R., Hartmann, M., Hollister, E. B., et al. (2009). Introducing mothur: open-source, platform-independent, community-supported software for describing and comparing microbial communities. Appl. Environ. Microbiol. 75, 7537-7541. doi: 10.1128/aem. 01541-09

Schmitt, H., Stoob, K., Hamscher, G., Smit, E., and Seinen, W. (2006). Tetracyclines and tetracycline resistance in agricultural soils: microcosm and field studies. Microb. Ecol. 51, 267-276. doi: 10.1007/s00248-006-9035-y

Schmittgen, T. D., and Livak, K. J. (2008). Analyzing real-time PCR data by the comparative $C_{\mathrm{T}}$ method. Nat. protoc. 3, 1101-1108. doi: 10.1038/nprot.2008.73

Schreiter, S., Ding, G.-C., Heuer, H., Neumann, G., Sandmann, M., Grosch, R., et al. (2014). Effect of the soil type on the microbiome in the rhizosphere of field-grown lettuce. Front. Microbiol. 5:144. doi: 10.3389/fmicb.2014.00144

Schwaiger, K., Harms, K., Holzel, C., Meyer, K., Karl, M., and Bauer, J. (2009). Tetracycline in liquid manure selects for co-occurrence of the resistance genes tet(M) and tet(L) in Enterococcus faecalis. Vet. Microbiol. 139, 386-392. doi: $10.1016 /$ j.vetmic.2009.06.005

Shaffer, J. P., U'Ren, J. M., Gallery, R. E., Baltrus, D. A., and Arnold, A. E. (2017). An endohyphal bacterium (Chitinophaga, Bacteroidetes) alters carbon source use by Fusarium keratoplasticum (F. solani species complex, Nectriaceae). Front. Microbiol. 8:350. doi: 10.3389/fmicb.2017.00350

Shamseldin, A. (2013). The role of different genes involved in symbiotic nitrogen fixation-review. Glob. J. Biotechnol. Biochem. 8, 84-94.

Shen, J.-P., Zhang, L.-M., Guo, J.-F., Ray, J. L., and He, J.-Z. (2010). Impact of long-term fertilization practices on the abundance and composition of soil bacterial communities in Northeast China. Appl. Soil Ecol. 46, 119-124. doi: 10.1016/j.apsoil.2010.06.015

Sloan, J., McMurry, L. M., Lyras, D., Levy, S. B., and Rood, J. I. (1994). The Clostridium perfringens Tet $\mathrm{P}$ determinant comprises two overlapping genes: $\operatorname{tet} A(\mathrm{P})$, which mediates active tetracycline efflux, and $\operatorname{tet} B(\mathrm{P})$, which is related to the ribosomal protection family of tetracycline-resistance determinants. Mol. Microbiol. 11, 403-415. doi: 10.1111/j.1365-2958.1994.tb00320.x

Smalla, K., Wieland, G., Buchner, A., Zock, A., Parzy, J., Kaiser, S., et al. (2001). Bulk and rhizosphere soil bacterial communities studied by denaturing gradient gel electrophoresis: plant-dependent enrichment and seasonal shifts revealed. Appl. Environ. Microbiol. 67, 4742-4751. doi: 10.1128/AEM.67.10.4742-4751.2001

Song, C., Schmidt, R., Jager, V., Krzyzanowska, D., Jongedijk, E., Cankar, K., et al. (2015). Exploring the genomic traits of fungus-feeding bacterial genus Collimonas. BMC Genomics 16:1103. doi: 10.1186/s12864-015-2289-3

Su, J.-Q., Wei, B., Ou-Yang, W.-Y., Huang, F.-Y., Zhao, Y., Xu, H.-J., et al. (2015). Antibiotic resistome and its association with bacterial communities during sewage sludge composting. Environ. Sci. Technol. 49, 7356-7363. doi: 10.1021/ acs.est.5b01012
Sun, J., Zhang, Q., Zhou, J., and Wei, Q. (2014). Pyrosequencing technology reveals the impact of different manure doses on the bacterial community in apple rhizosphere soil. Appl. Soil Ecol. 78, 28-36. doi: 10.1016/j.apsoil.2014. 02.004

Tien, Y. C., Li, B., Zhang, T., Scott, A., Murray, R., Sabourin, L., et al. (2017). Impact of dairy manure pre-application treatment on manure composition, soil dynamics of antibiotic resistance genes, and abundance of antibiotic-resistance genes on vegetables at harvest. Sci. Total Environ. 58, 32-39. doi: 10.1016/j. scitotenv.2016.12.138

Tylová, T., Olsovská, J., Novák, P., and Flieger, M. (2010). High-throughput analysis of tetracycline antibiotics and their epimers in liquid hog manure using ultra performance liquid chromatography with UV detection. Chemosphere 78, 353-359. doi: 10.1016/j.chemosphere.2009. 11.020

Udikovic-Kolic, N., Wichmann, F., Broderick, N. A., and Handelsman, J. (2014). Bloom of resident antibiotic-resistant bacteria in soil following manure fertilization. Proc. Natl. Acad. Sci. U.S.A. 111, 15202-15207. doi: 10.1073/pnas. 1409836111

van den Meersche, T., van Pamel, E., van Poucke, C., Herman, L., Heyndrickx, M., Rasschaert, G., et al. (2016). Development, validation and application of an ultra high performance liquid chromatographic-tandem mass spectrometric method for the simultaneous detection and quantification of five different classes of veterinary antibiotics in swine manure. J. Chromatogr. A 1429, 248-257. doi: 10.1016/j.chroma.2015.12.046

van Elsas, J. D., Turner, S., and Bailey, M. J. (2003). Horizontal gene transfer in the phytosphere. New Phytol. 157, 525-537. doi: 10.1046/j.1469-8137.2003. 00697.x

Wang, F. H., Qiao, M., Chen, Z., Su, J. Q., and Zhu, Y. G. (2015). Antibiotic resistance genes in manure-amended soil and vegetables at harvest. J. Hazard. Mater. 299, 215-221. doi: 10.1016/j.jhazmat.2015.05.028

Wellington, E. M. H., Boxall, A. B. A., Cross, P., Feil, E. J., Gaze, W. H., Hawkey, P. M., et al. (2013). The role of the natural environment in the emergence of antibiotic resistance in Gram-negative bacteria. Lancet Infect. Dis. 13, 155-165. doi: 10.1016/s1473-3099(12)70317-1

WHO (2014). Antimicrobial Resistance: Global Report on Surveillance. Geneva: World Health Organization.

Wichmann, F., Udikovic-Kolic, N., Andrew, S., and Handelsman, J. (2014). Diverse antibiotic resistance genes in dairy cow manure. MBio 5:e01017. doi: 10.1128/ mBio.01017-13

Widyasari-Mehta, A., Hartung, S., and Kreuzig, R. (2016). From the application of antibiotics to antibiotic residues in liquid manures and digestates: a screening study in one European center of conventional pig husbandry. J. Environ. Manag. 177, 129-137. doi: 10.1016/j.jenvman.2016.04.012

Wistrand-Yuen, E., Knopp, M., Hjort, K., Koskiniemi, S., Berg, O. G., and Andersson, D. I. (2018). Evolution of high-level resistance during lowlevel antibiotic exposure. Nat. Commun. 9:1599. doi: 10.1038/s41467-01804059-1

Wolters, B., Jacquiod, S., Sørensen, S. J., Widyasari-Mehta, A., Bech, T. B., Kreuzig, R., et al. (2018). Bulk soil and maize rhizosphere resistance genes, mobile genetic elements and microbial communities are differently impacted by organic and inorganic fertilization. FEMS Microbiol. Ecol. 94:fiy027. doi: 10.1093/femsec/fiy027

Wolters, B., Widyasari-Mehta, A., Kreuzig, R., and Smalla, K. (2016). Contaminations of organic fertilizers with antibiotic residues, resistance genes, and mobile genetic elements mirroring antibiotic use in livestock? Appl. Microbiol. Biotechnol. 100, 9343-9353. doi: 10.1007/s00253-016$7742-\mathrm{y}$

Xiong, W., Sun, Y., Ding, X., Wang, M., and Zeng, Z. (2015). Selective pressure of antibiotics on ARGs and bacterial communities in manure-polluted freshwatersediment microcosms. Front. Microbiol. 6:194. doi: 10.3389/fmicb.2015. 00194

Yan, Q., Li, X., Ma, B., Zou, Y., Wang, Y., Liao, X., et al. (2018). Different concentrations of doxycycline in swine manure affect the microbiome and degradation of doxycycline residue in soil. Front. Microbiol. 9:3129. doi: 10. 3389/fmicb.2018.03129

Yang, Q., Tian, T., Niu, T., and Wang, P. (2017). Molecular characterization of antibiotic resistance in cultivable multidrug-resistant bacteria from livestock manure. Environ. Pollut. 229, 188-198. doi: 10.1016/j.envpol.2017.05.073 
Yang, Q., Wang, R., Ren, S., Szoboszlay, M., and Moe, L. A. (2016). Practical survey on antibiotic-resistant bacterial communities in livestock manure and manureamended soil. J. Environ. Sci. Health B 51, 14-23. doi: 10.1080/03601234.2015. 1080481

Zhang, Q., Sun, J., Liu, S., and Wei, Q. (2013). Manure refinement affects apple rhizosphere bacterial community structure: a study in sandy soil. PLoS One 8:e76937. doi: 10.1371/journal.pone.0076937

Zhang, Y.-J., Hu, H.-W., Gou, M., Wang, J.-T., Chen, D., and He, J.-Z. (2017). Temporal succession of soil antibiotic resistance genes following application of swine, cattle and poultry manures spiked with or without antibiotics. Environ. Pollut. 231, 1621-1632. doi: 10.1016/j.envpol.2017.09.074

Zhao, Y., Su, J. Q., An, X. L., Huang, F. Y., Rensing, C., Brandt, K. K., et al. (2017). Feed additives shift gut microbiota and enrich antibiotic resistance in swine gut. Sci. Total Environ. 621, 1224-1232. doi: 10.1016/j.scitotenv.2017. 10.106

Zhu, Y.-G., Johnson, T. A., Su, J.-Q., Qiao, M., Guo, G.-X., Stedtfeld, R. D., et al. (2013). Diverse and abundant antibiotic resistance genes in Chinese swine farms. Proc. Natl. Acad. Sci. U.S.A. 110, 3435-3440. doi: 10.1073/pnas 1222743110

Conflict of Interest Statement: The authors declare that the research was conducted in the absence of any commercial or financial relationships that could be construed as a potential conflict of interest.

The reviewer JW declared a shared affiliation, with no collaboration, with one of the authors, Y-GZ, to the handling Editor at the time of review.

Copyright (C) 2019 Blau, Jacquiod, Sørensen, Su, Zhu, Smalla and Jechalke. This is an open-access article distributed under the terms of the Creative Commons Attribution License (CC BY). The use, distribution or reproduction in other forums is permitted, provided the original author(s) and the copyright owner(s) are credited and that the original publication in this journal is cited, in accordance with accepted academic practice. No use, distribution or reproduction is permitted which does not comply with these terms. 